\title{
ANALISIS FAKTOR INDEKS PEMBANGUNAN MANUSIA DI KABUPATEN LANDAK MENGGUNAKAN MODEL REGRESI SPASIAL
}

\author{
MUHAMMAD FIRMAN ANNUR \\ Program Studi Pendidikan Matematika STKIP Pamane Talino, \\ Jl. Afandi Rani Jalur 2 Ngabang Kabupaten Landak Kalimantan Barat Indonesia \\ m.annur@stkippamanetalino.ac.id
}

First Received: DD-MM-YYYY; Accepted: DD-MM-YYYY

\begin{abstract}
Abstrak
Regresi merupakan model analisis yang digunakan untuk mengetahui pengaruh satu atau lebih variabel bebas terhadap suatu variabel terikat. Tujuan penelitian ini untuk mengetahui pengaruh variabel angka harapan hidup, pengeluaran per kapita, dan angka harapan sekolah terhadap indeks pembangunan manusia. Adapun populasi pada penelitian ini adalah seluruh kecamatan di kabupaten Landak. Pada penelitian ini model regresi spasial digunakan untuk mengetahui pengaruh angka harapan hidup, pengeluaran per kapita dan angka harapan pendidikan terhadap indeks pembangunan manusia. Hasil penelitian memperlihatkan Model Error Spasial merupakan model terbaik dalam penelitian ini dan variabel angka harapan hidup, pengeluaran per kapita, dan angka harapan hidup berpengaruh terhadap indeks pembangunan manusia.
\end{abstract}

Kata kunci: Regresi spasial; SEM; SAR; Indeks Pembangunan Manusia

\section{FACTOR ANALYSIS FOR HUMAN DEVELOPMENT REPORT OF LANDAK REGENCY BY USING SPATIAL REGRESSION MODEL}

\begin{abstract}
Regression is analysis model used to determine the effect of a independent variable or more to a dependent variable. The aim of this research to determine the effect of life expentancy, expenditure per capita, education expentancy to human development reports. The population of this research are entire sub-district of Landak Regency. In this research, Spatial regression model was used to determine whether life expentacy, expenditure per capita and education have effect on human development. Based on the result, it concludes that SEM (Spatial Error Model) is the best model for this research. Futhermore, life expentancy, expenditure per capita, and education expentancy have effect to human development report.
\end{abstract}

Keywords: Spatial regression; SEM; SAR; Human development report

\section{PENDAHULUAN}

Indeks pembangunan manusia (IPM) merupakan tolok ukur capaian pembangunan manusia berbasis sejumlah komponen dasar kualitas hidup (BPS, 2014, p. 10). IPM menjelaskan bagaimana penduduk dapat mengakses hasil pembangunan dalam memperoleh pendapatan, kesehatan, pendidikan, dan sebagainya. Sebagai ukuran kualitas hidup, IPM 
dibangun melalui tiga dimensi dasar yaitu: (i) umur panjang dan hidup sehat; (ii) pengetahuan; dan (iii) standar hidup layak. Secara umum, Indeks pembangunan manusia di Kabupaten Landak terus meningkat, di tahun 2010 IPM Landak berkisar di angka 60,36 dan di tahun 2018 meningkat menjadi 65,45.

Analisis regresi diperlukan untuk menemukan faktor-faktor apa saja yang mempengaruhi IPM di Kabupaten Landak dari tahun ke tahun. Pada pemodelan data seringkali ditemukan pengamatan pada suatu lokasi memiliki pengaruh dengan lokasi lain yang berdekatan atau yang biasa disebut dengan ketergantungan spasial. Model yang digunakan untuk mengetahui adanya pengaruh dari variabel bebas terhadap variabel terikat dengan memperhatikan ketergantungan spasial inilah yang dinamakan model regresi spasial. Pada penelitian ini, model regresi spasial untuk memeriksa apakah angka harapan hidup, pengeluaran per kapita dan angka harapan hidup mempengaruhi indeks pembangunan manusia di Kabupaten Landak.

\section{Analisis Regresi}

Analisis regresi merupakan pemodelan matematika untuk mengetahui pengaruh variabel $x$ selaku variabel bebas yang mempengaruhi variabel $y$ sebagai variabel terikat (Sukestiyarno, 2013).

\section{Analisis Regresi Sederhana}

Analisis regresi sederhana digunakan untuk menjelaskan pengaruh antara satu variabel bebas dengan variabel terikat. Modelnya sebagai berikut [1]:

$$
y_{i}=\beta_{0}+\beta_{j} X_{i j}+\varepsilon_{i}, i=1,2, \ldots . \text { dan } j=1,2, . . k
$$

\section{Analisis Regresi Berganda}

Analisis regresi berganda adalah analisis regresi yang memproses pengaruh lebih dari satu variabel bebas terhadap suatu variabel terikat (Sukestiyarno, 2013). Modelnya secara umum ialah sebagai berikut [2]:

$$
y_{i}=\beta_{0}+\sum_{j=1}^{k} \beta_{j} X_{i j}+\varepsilon_{i}
$$

\section{Pemodelan Spasial}

Menurut Mills dan Patterson (2009) menghilangkan efek spasial dalam suatu persamaan bukanlah hal yang baik untuk dilakukan karena akan menghasilkan parameter yang bias dan 
tidak konsisten. Oleh karenanya diperlukan model yang memiliki pendekatan spasial, yakni pemodelan yang berhubungan dengan titik dan area. Terdapat beberapa bentuk pemodelan spasial, diantaranya:

\section{Spasial Autoregressive Model (SAR)}

Model ini ialah pengkombinasian model regresi sederhana dengan lag spasial pada variabel terikat dengan menggunakan dara cross section. Model umum SAR ialah sebagai berikut (Baltagi \& Liu, 2012) [3]:

$$
\begin{aligned}
& y=\rho W y+X \beta+\varepsilon, \\
& \varepsilon_{i} \sim N\left(0, \sigma^{2} I\right)
\end{aligned}
$$

Koefisien lag spasial $(\rho)$ menunjukkan tingkat pengaruh dari suatu lokasi terhadap lokasi disekitarnya (Samadi dkk, 2016).

\section{Spatial Error Model (SEM)}

Model ini merupakan model spasial dengan errornya memiliki korelasi spasial. Model SEM ditunjukkan dengan persamaan berikut [4]:

$$
\begin{aligned}
& y=X \beta\left|\lambda W_{2 \mu}\right| \varepsilon, \\
& \varepsilon \sim N\left(0, \sigma^{2} I\right)
\end{aligned}
$$

Dengan koefisien $(\lambda)$ menunjukkan tingkat pengaruh error spasial dari suatu lokasi terhadap lokasi lain di sekitarnya.

\section{Matriks Pembobot Spasial}

Matriks pembobot spasial ialah matriks ketergantungan spasial (contiguity). Berikut persamaan matriksnya [5]:

$$
w_{i j}=\frac{c_{i j}}{\sum_{t=1}^{k} c_{i j}}
$$

Matriks $\mathrm{C}$ mempunyai entri $c_{i j}=1$ jika dua pengamatan $i$ dan $j$ dianggap berhubungan (bertetangga), dan $c_{i j}=0$ jika tidak berhubungan antara pengamatan $i$ dan $j$. Matriks $\mathrm{W}$ adalah matriks $\mathrm{C}$ yang telah dinormalisasi baris dimana jumlah tiap baris $c_{i}$ sama dengan 1 dan diagonal dari matriks yang diisi nol. Dimensi matriks ini adalah $n \times n$, dengan $n$ adalah 
banyaknya lokasi. Isi dari matriks pembobot spasial pada baris ke- $i$ dan kolom ke-j adalah $w_{i j}$ (Samadi dkk, 2015).

\section{Efek Spasial}

Efek Heterosekesdastitas

Efek ini merupakan efek yang menunjukkan adanya keragaman antar lokasi. Setiap lokasi memiliki struktur dan parameter hubungan yang berbeda (Samadi, dkk, 2015). Pengujiannya menggunakan uji Breusch-Pagan test (BP tes) sebagai berikut [6]:

$$
B P=\left(\sum_{i=1}^{n} x_{i} f_{i}\right)\left(\sum_{i=1}^{n} x_{i} x_{i}^{T}\right)
$$

Indeks Moran

Indeks Moran atau Koefisien Moran I digunakan untuk uji dependensi spasial atau autokorelasi antar lokasi. Persamaan Indeks Moran adalah sebagai berikut [7]:

$$
I=\frac{n \sum_{j \neq i}^{k} w_{i j}\left(y_{i}-\bar{y}\right)\left(y_{j}-\bar{y}\right)}{\left(\sum_{i} \sum_{j \neq i}\right) \sum i\left(y_{i}-\bar{y}\right)^{2}}
$$

Lagrange Multiplier (LM) Test

Uji LM (Lagrange Multiplier) adalah uji untuk menentukan ada tidaknya efek spasial pada suatu model. Bentuk tes LM (Anselin, 1988) yaitu:

Pada SEM:

$H_{0}: \lambda=0$ tidak terdapat ketergantungan spasial pada galat

$H_{1}: \lambda \neq 0$ terdapat ketergantungan spasial pada galat

Formula ujinya [8]:

$$
\begin{aligned}
& L M_{\lambda}=\left(\frac{1}{T}\right)\left(\frac{e^{\prime} W y}{\sigma^{2}}\right)^{2} \sim X^{2}(1) \\
& T=\operatorname{trace}\left(W+W^{\prime}\right) * W \\
& \sigma^{2}=\frac{e^{\prime} e}{n}
\end{aligned}
$$

$H_{0}$ diputuskan akan ditolak jika nilai $L M_{\lambda}>\chi^{2} \alpha(\rho)$ tabel, dengan nilai $\rho$ adalah jumlah parameter spasial.

Pada SAR:

Hipotesisnya adalah:

$H_{0}: \rho=0$ tidak terdapat ketergantungan spasial pada variabel respon

$H_{1}: \rho \neq 0$ terdapat ketergantungan spasial pada variabel respon 
Formula ujinya [9]:

$$
\begin{aligned}
& L M_{\rho}=\left(\frac{e^{\prime} W e}{\sigma^{2}}\right)\left[T_{22}-\left(T_{21}\right)^{2} \operatorname{var}(\rho)\right]^{-1} \sim X^{2}(1) \\
& T_{22}=\operatorname{trace}\left(W^{*} W+W^{\prime} W\right) \\
& T_{21}=\operatorname{trace}\left(W^{*} C A+W^{\prime} C A^{-1}\right)
\end{aligned}
$$

$H_{0}$ diputuskan akan ditolak jika nilai $L M_{\rho}>\chi^{2} \alpha(\rho)$ tabel, dengan nilai $\rho$ adalah jumlah parameter spasial

\section{Indeks Pembangunan Manusia}

Pembangunan manusia berarti pertumbuhan yang positif dan perubahan dalam tingkat kesejahteraan. Hal ini harus terjadi pada semua aspek kehidupan, baik ekonomi, sosial, politik, budaya, dan lingkungan. Oleh karena itu, fokus utama pembangunan manusia untuk memperluas jangkauan pilihan mereka dalam upaya memenuhi aspirasinya (BPS, 2014).

Komponen IPM meliputi 3 (tiga) dimensi kesehatan, dimensi pendidikan, dan dimensi pengeluaran. Formula yang digunakan dalam penghitungan indeks komponen IPM adalah sebagai berikut:

Dimensi Kesehatan [10]:

$$
I_{\text {Kesehatan }}=\frac{A H H-A H H_{\text {min }}}{A H H_{\text {maks }}-A H H_{\text {min }}}
$$

Dimensi Pendidikan [11]:

$$
\begin{gathered}
I_{H L S}=\frac{H L S-H L S_{\min }}{H L S_{\text {maks }}-H L S_{\text {min }}} \\
I_{R L S}=\frac{R L S-R L S_{\text {min }}}{R L S_{\text {maks }}-R L S_{\text {min }}} \\
I_{\text {pendidikan }}=\frac{I_{H L S}-I_{R L S}}{2}
\end{gathered}
$$

Dimensi Pengeluaran [12]:

$$
I_{\text {pengeluaran }}=\frac{\ln (\text { pengeluaran })-\ln (\text { pengeluaran }}{\ln \left(\text { pengeluaran }_{\text {maks }}\right)-\ln \left(\text { pngeluaran }_{\min }\right)}
$$

Formula IPM [13]:

$$
I P M=\sqrt[3]{I_{\text {Kesehatan }} \times I_{\text {pendidikan }} \times I_{\text {pengeluaran }}} \times 100
$$

(Fauzi, 2016) 


\section{Aplikasi Geoda}

Geoda adalah inkarnasi terbaru dari kumpulan software yang dirancang untuk melaksanakan teknik eksplorasi analisis data spasial, seperti deskriptif analisis, statistik autokorelasi dan indikator outlier spasial. Geoda berkesesuaian dengan file berbentuk ESRI sebagai standar untuk menyimpan informasi spasial. Pada penelitian ini, aplikasi Geoda digunakan untuk operasikan analisis regresi linear berganda (OLS) kemudian menentukan model regresi mana yang terbaik untuk dipilih. Geoda memudahkan peneliti untuk menganalisis data regresi spasial.

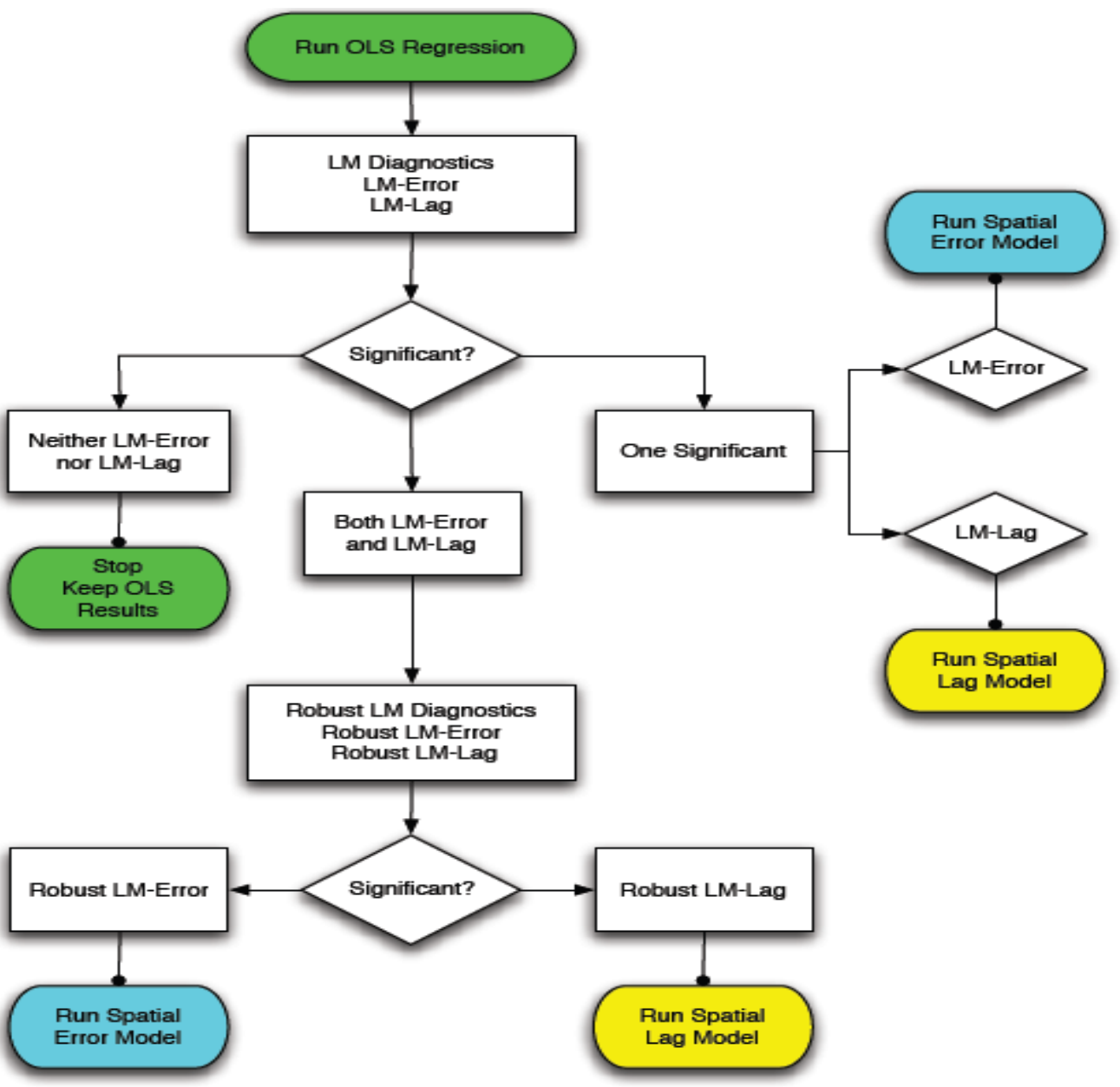

Gambar 1. Bagan Alur Proses Pengambilan Keputusan pada Regresi Spasial

Pada penggunaan aplikasi Geoda, SAR atau LM-lag dan SEM atau LM-Error diuji dengan cara membandingkan masing-masing nilai $\rho$ dengan $\alpha=0,05$. Pada LM-lag dan LMError dikatakan signifikan jika $\rho<\alpha=0,05$. Jika kedua-duanya signifikan dilanjutkan dengan uji lanjutan yaitu Robust LM-Error dan Robust LM-Lag dengan tetap dibandingkan dengan $\alpha=0,05$. Jika didapat Robust LM-Lag signifikan maka dapat disimpulkan SAR (Spasial Autoregressive Model) merupakan pemodelan terbaik untuk menggambarkan 
regresinya, sebaliknya jika Robust LM-Error yang signifikan maka SEM (Spatial Error Model) yang menjadi model regresi terbaik.

\section{METODE PENELITIAN}

Penelitian ini menggunakan data sekunder yaitu data dan berita resmi yang telah diolah dan disajikan oleh Badan Pusat Statistik Kabupaten Landak tentang indeks pembangunan manusia. Variabel yang digunakan dalam penelitian ini adalah indeks pembangunan manusia sebagai variabel terikat $(\mathrm{Y})$ dan variabel bebas yang terdiri dari angka harapan hidup $\left(\mathrm{X}_{1}\right)$, Pendapatan per Kapita $\left(\mathrm{X}_{2}\right)$ dan angka harapan sekolah $\left(\mathrm{X}_{3}\right)$. Adapun langkah-langkah analisis data yang dilakukan pada penelitian ini adalah sebagai berikut: 1) Melakukan pengujian parameter model regresi linier berganda dan menguji asumsi error (uji homogenitas, uji autokorelasi, dan uji normalitas). 2) Menentukan matriks pembobot spasial W. 3) Menentukan nilai Indeks Moran. 4) Menguji efek ketergantungan spasial dengan uji Lagrange Multiplier. 5) Melakukan pengujian parameter model regresi spasial terpilih berdasarkan uji Lagrange Multiplier. 6) Menentukan faktor-faktor yang mempengaruhi indeks pembangunan manusia berdasarkan model regresi spasial terpilih

\section{HASIL DAN PEMBAHASAN}
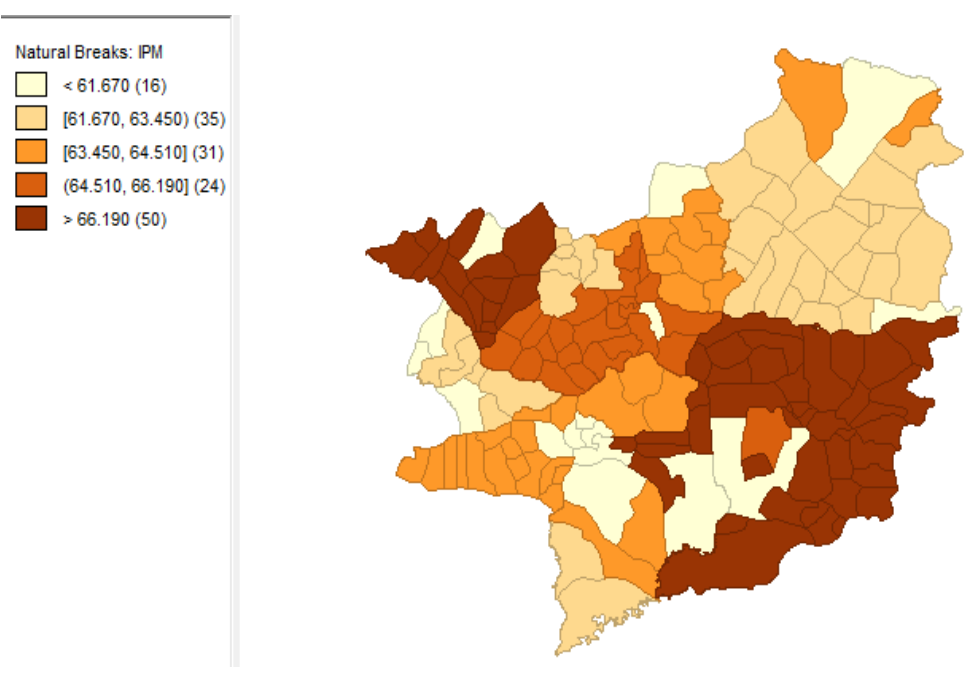

Gambar 2. Peta Kabupaten Landak Berdasarkan Tingkat Indeks Pembangunan Manusia

Peta di atas merupakan peta Kabupaten Landak dengan melihat tingkat Indeks Pembangunan Manusia (IPM). Tingkat IPM pada peta tersebut terbagi dalam 5 (lima) tingkatan. Tingkat pertama pada nilai IPM > 61,67, tingkat kedua IPM-nya 61,67 - 63,45, 
tingkat ketiga dengan nilai IPM 63,451 - 64,510, tingkat keempat nilai IPM-nya 64,511 66,19 dan tingkat terakhir dengan nilai IPM > 66,19.

Berdasarkan pemodelan menggunakan model regresi linear berganda, didapati variabel $\mathrm{X}_{1}$ (angka harapan hidup), $\mathrm{X}_{2}$ (pendapatan per kapita) dan $\mathrm{X}_{3}$ (angka harapan sekolah) berpengaruh signifikan dengan $\alpha=0,05$. Persamaan regresi yang terbentuk menggunakan metode kuadrat terkecil (MKT) adalah:

$$
y=-1015,61+14,407 X_{1}+0,00359994 X_{2}+1,66475 X_{3}
$$

Persamaan regresi yang terbentuk mempunyai nilai $\mathrm{R}^{2}$ sebesar $88,48 \%$. Ini artinya model regresi dapat menjelaskan keragaman Indeks Pembangunan Manusia sebesar 88,48\%, sedangkan $11,52 \%$ sisanya dijelaskan oleh variabel lain di luar model.

\section{Indeks Moran}

Hasil Indeks Moran untuk sisaan model MKT Indeks Pembangunan Manusia memperoleh nilai Indeks Moran sebesar 13,3562 dengan nilai-p adalah 0 lebih kecil $\alpha=$ 0,05. Hal ini menunjukkan bahwa terdapat autokorelasi spasial pada Indeks pembangunan manusia.

\section{Indentifikasi Efek Spasial}

Indentifikasi ini digunakan untuk mengetahui adanya ketergantungan spasial pada model regresi yang berpengaruh terhadap Indeks pembangunan manusia. Uji Lagrange Multiplier (LM) dilakukan untuk menguji efek ketergantungan spasial dalam lag dan error. Hasil yang diperoleh dari uji Lagrange Multiplier menjadi dasar bentuk model regresi spasial.

\begin{tabular}{|c|c|c|c|}
\hline TEST & $\mathrm{MI} / \mathrm{DF}$ & VALUE & PROB \\
\hline Moran's I (error) & 0.6434 & 13.3562 & 0.00000 \\
\hline Lagrange Multiplier (lag) & 1 & 41.3328 & 0.00000 \\
\hline Robust IM (lag) & 1 & 1.5279 & 0.21643 \\
\hline Lagrange Multiplier & 1 & 158.8278 & 0.00000 \\
\hline Robust IM (error) & 1 & 119.0229 & 0.00000 \\
\hline Lagrange Multiplier (SARMA) & 2 & 160.3557 & 0.00000 \\
\hline
\end{tabular}

Gambar 3. Output dari hasil perhitungan analisis regresi pada aplikasi Geoda

Berdasarkan tabel di atas dapat dilihat nilai $\rho$ (PROB) pada lag Lagrange Multiplier dan error Lagrange Multiplier nilainya lebih kecil dari $\alpha=0,05$. Ini artinya kedua model signifikan. Untuk mendapatkan model terbaik perbandingan antara LM (lag) dan LM (error) dilanjutkan dengan membandingkan Robust LM (lag) dan Robust LM (error) (Anselin, 2010). 
Dapat diperhatikan bahwa yang signifikan adalah Robust LM (error) dengan nilai 0 lebih kecil dari $\alpha=0,05$.

Berdasarkan hasil tersebut dapat disimpulkan $\mathrm{H}_{0}$ ditolak artinya terdapat ketergantungan error spasial sehingga kemudian dapat dilanjutkan pada pembuatan model SEM. Uji LM yang ditunjukkan oleh Robust LM (lag) memberikan $p$-value yang lebih besar dari $\alpha=0,05$ yang menunjukkan bahwa tidak terdapat lag spasial sehingga tidak dapat melanjukan pembuatan model spasial lag.

\section{Spasial Error Model (SEM)}

$\begin{array}{crrrr}\text { Variable } & \text { Coefficient } & \text { Std. Error } & \text { z-value } & \text { Probability } \\ \text { CONSTANT } & -870.303 & 76.2605 & -11.4122 & 0.00000 \\ \text { Angka_idup } & 12.3726 & 1.06281 & 11.6414 & 0.00000 \\ \text { Penda_pita } & 0.00341721 & 0.000426963 & 8.00353 & 0.00000 \\ \text { Angka_olah } & 1.86059 & 0.250607 & 7.42434 & 0.00000 \\ \text { LAMBDA } & 0.854867 & 0.0425676 & 20.0826 & 0.00000\end{array}$

Gambar 4. Hasil Analisis regresi spasial dengan SEM

Melalui aplikasi Geoda, dilakukan pendugaan dan pengujian parameter Model SEM dengan menggunakan tiga variabel yang berpengaruh terhadap variabel terikat. Variabel $\mathrm{X}_{1}$ (angka harapan hidup), $\mathrm{X}_{2}$ (pendapatan per kapita), dan $\mathrm{X}_{3}$ (angka harapan sekolah) dan galat spasial $(\lambda)$ secara signifikan berpengaruh terhadap indeks pembangunan manusia di kabupaten Landak dengan $\alpha=0,05$. Model regresi yang terbentuk pada indeks pembangunan manusia menggunakan model error spasial adalah:

$$
\begin{aligned}
& y_{i}=-870,303+12,3726 X_{1 i}+0,0034 X_{2 i}+1,8605 X_{3 i}+\lambda_{i} \\
& \lambda_{i}=0,8548 \sum_{j=1, i \neq j}^{n} w_{i j} \lambda_{j}+\varepsilon_{i} \text { dimana } i=1,2,3, \ldots 13
\end{aligned}
$$

\section{Dengan}

$y_{i}=$ IPM di kecamatan ke-i

$\lambda_{i}=$ Error spasial dari kecamatan ke-i

$\lambda_{j}=$ Error spasial dari tetangga kecamatan ke-i

$w_{i j}=$ elemen matriks pembobot spasial yang sudah dinormalisasi baris 


\section{Interpretasi Model Error Spasial (SEM)}

Koefisien menunjukkan adanya hubungan Indeks pembangunan manusia pada suatu wilayah dengan wilayah lain yang berdekatan. Koefisien pendapatan per kapita sebesar 0,00341721 menunjukkan bahwa setiap peningkatan pendapatan per kapita di Kabupaten Landak sebesar satu satuan akan meningkatkan indeks pembangunan manusia sebesar 0,00341721 satuan dengan asumsi variabel-variabel lain dianggap konstan.

\section{SIMPULAN}

Berdasarkan hasil pembahasan dan analisis dapat ditarik kesimpulan sebagai berikut:

1. Model Error Spasial (SEM) terpilih sebagai model regresi spasial yang terbaik dibanding SAR dan Regresi linear berganda (berdasarkan output aplikasi Geoda) dalam menentukan faktor-faktor yang mempengaruhi indeks pembangunan manusia di kecamatan Kabupaten Landak. Model SEM yang terbentuk adalah:

$$
\begin{aligned}
& y_{i}=-870,303+12,3726 X_{1 i}+0,0034 X_{2 i}+1,8605 X_{3 i}+\lambda_{i} \\
& \lambda_{i}=0,8548 \sum_{j=1, i \neq j}^{n} w_{i j} \lambda_{j}+\varepsilon_{i} \text { dimana } i=1,2,3, \ldots 13
\end{aligned}
$$

2. Berdasarkan model terbaik yang didapat yaitu model error spasial maka faktor-faktor yang mempengaruhi indeks pembangunan manusia di kecamatan Kabupaten Landak adalah angka harapan hidup, pendapatan per kapita, dan angka harapan sekolah.

\section{DAFTAR PUSTAKA}

Anselin, L. (1988). Spatial Econometrics: Method and Models. Academic Publish-ers, Dordrecht.

Anselin, L.(2010). Prespective on Spatial Data Analysis.New York:Springer.

Baltagi H. Badi \& Long Liu. (2012). Testing for Spatial Lag and Spatial Error Dependence Using Doble Length Artifical Regressions. Stat Papers(2014)55: 477-486

BPS, (2014). Indeks Pembangunan Manusia Metode Baru. Jakarta:BPS.

Fauzi, F. (2016). Model Regresi Spasial Terbaik Indeks Pembangunan Manusia Provinsi Jawa Tengah. Skripsi. Semarang: FMIPA Universitas Negeri Semarang

Mills, Terence C \& Patterson, Kerry. (2009). Palgrove Handbook of Econometrics. Scince.New York:Springer. 
Rati, M.. 2013. Model regresi spasial untuk anak tidak bersekolah usia kurang 15 tahun di kota medan. Skripsi. Medan: FMIPA Universitas Sumatra Utara.

Samadi, dkk. 2016. Penerapan Model Regresi Spasial dalam Menentukan Faktor-Faktor yang Mempengaruhi Indeks Pembangunan Manusia di Kabupaten/Kota Provinsi Sumatera Barat. Jurnal Matematika UNAND. Vol VI No. 4 (80-89). ISSN: 2303-2910.

Suksetiayarno. 2013. Olah Data Penelitian Berbantuan SPSS. Semarang: Universitas Negeri Semarang. 